\title{
Carta a Ignacio Ellacuría
}

\author{
P. Jon Sobrino S.J.
}

Querido Ellacu:

En este octavo aniversario les seguimos recordando, y te quiero contar un año más nuestras venturas y desventuras. Ante todo, quiero decirte que "no los olvidamos", aunque no todos los recuerdan, por supuesto. La modernización del pals facilita la tolerancia, pero todavía no hay agallas para que los estamentos oficiales y poderosos los recuerden, agradezcan el aporte de sus vidas y el amor de sus muertes. Esto solfa enojarme, pero lo he aceptado como parte del misterio de oscuridad y de iniquidad. A los mejores les dieron muerte y ahora quieren mantenerlos bien enterrados. Hernos mejorado en modos, Ellacu, pero las mejoras no llegan a la honradez de pedir perdón, ni menos — pues el perdón dado está - a la honradez del agradecimiento.

Todo esto me trae a la mente al gran inquisidor de Dostoyevski. Este alto funcionario eclesiástico conocía a Jesucristo, claro está. Hasta que un $\mathrm{d} l a$ se le apareció Jesucristo en persona. Hablaron, y al final el inquisidor le dijo: "Señor, no vuelvas". Este "no vuelvas" me parece uno de los graves males de nuestro pals y de nuestro mundo. Cuando se juntan los grandes en las Naciones Unidas o en otros foros internacionales, ustedes los mártires no están presentes, no los hacen volver.

Y no sólo en esos foros. Tampoco la Iglesia oficial hace mucho para recordarlos. En 1992, en documentos preparatorios para la reunión de Santo Domingo habra bellas páginas sobre los mártires latinoamericanos, y por cierto allf estaban Monseńor Romero, Julia Elba y ustedes los de la UCA. Pero después, como si una misteriosa mano invisible quisiera hacer volver las cosas a la normalidad de las curias, en el documento final ustedes prácticamente desaparecieron. $Y$ en nuestros días, por primera vez en la historia de la Iglesia, va a tener lugar un sínodo de todas las Américas, desde Canadá hasta la Patagonia, y el documento preparatorio tampoco les toma a ustedes en serio. Por coincidencia, el sínodo comienza en Roma el 16 de noviembre, a la misma hora en que aquí estaremos celebrando la vigilia. 
Estos son pequeños desahogos, Ellacu, para recordar lo que tenemos bien sabido. Lo hago con humor, como nos decía sabiamente González Faus. También lo hago con impotencia, pues no es nada fácil tumbar el muro de silencio, indiferencia y - con frecuencia- de mentira que los grandes inventos modernos, llamados modernización y globalización, han levantado para ocultar lo humano y, ciertamente, para ocultar lo de ustedes: el gran amor. Pero lo digo también con "necedad" salvadoreña y cristiana.

Es un hecho que aquí en el país les recordamos. Cada año aumenta el número de visitantes, cantos, oraciones, lágrimas y alegrias... Pudiera no ser así, pero así es. De este pequefío país —al que le han querido robar muchas cosas de su cuerpo y de su alma - no ha desaparecido el agradecimiento. Es lo mejor de la necedad salvadoreña: con Monseñor a la cabeza, ustedes siguen presentes.

Pero mantenemos también la necedad cristiana: "Recuerda Israel”, decía Dios a su pueblo de Dios. "Hagan esto en mi recuerdo", decía Jesús partiendo el pan antes de partirse a sí mismo. Estamos claros que mientras tengamos el coraje de recordar, tendremos también la bendición de la esperanza. ¡Pobres y desgraciados los que les olvidan! Piensan $\longrightarrow$ al menos eso dicen- que están construyendo una sociedad distinta en que las lacras del pasado disminuyen o desaparecen. ¡Y ojalá tengan razón! Pero se quedan sin luz, sin ánimo, sin esperanza, sin aliento para mirar lejos y para mirar a todos. Don Pedro Casaldáliga, gran poeta, sabe decir bien las cosas, y lo ha dicho: “Ay de los pueblos que olvidan a sus mártires!”.

¿Y qué hay que recordar? Lo hacendosa y servicial que era Julia Elba, la bondad de Amando, el carisma de Polín, la predicación de aquel Jesús campesino, a quien Monseñor llamaba "el hombre del evangelio", la pasión por la verdad de Monseñor Romero... Y tantas cosas más... De ti, Ellacu, quiero recordar sólo dos cosas que buena falta nos hacen. Una, sobre nuestra historia. Otra, sobre nuestra Iglesia.

En Barcelona, una semana antes de ser asesinado dijiste estas palabras: "hay que revertir la historia". Paso a paso, y entre todos por supuesto. No eras tú ingenuo ni idealista, como nos lo recuerdan ahora quienes quieren enterrar lo que llaman entusiasmos utópicos. Pero tampoco eras cínico ni inmisericorde y, por eso, al ritmo del dolor del corazón llamabas a las cosas por su nombre. "Revertir" no es simplemente cambiar, ni aplicar cambios cosméticos, ni cambiar para que todo siga igual.

Pues bien, la verdad es que ha habido cambios en nuestro pals con el final de la guerra y los acuerdos de paz -cambios, por cierto, hechos posible en buena medida por el martirio de ustedes, cosa que ya no se recuerda. En estos cambios tiene mayor vigencia "el juego de la democracia", dicho sin ironía esto de “juego". Hay mayor libertad de expresión o, al menos, hay 


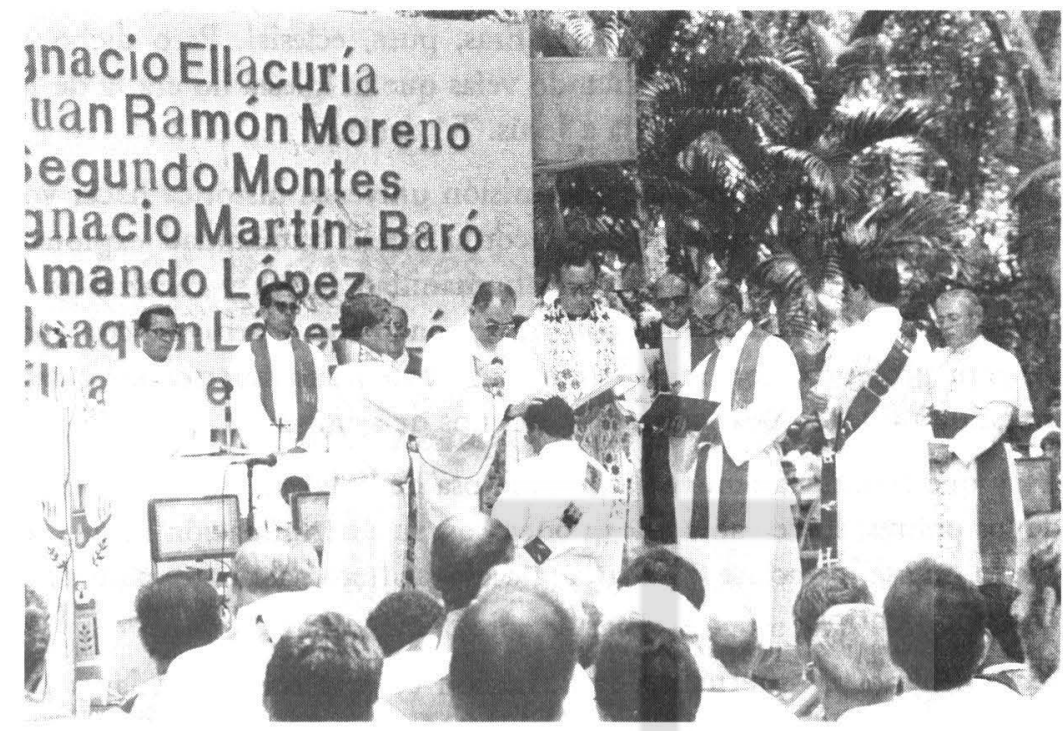

menos miedo a expresarse. Sobre todo, ha desaparecido prácticamente la barbarie oficial y las actividades terroristas.

Pero junto a estos cambios, hay cosas que siguen prácticamente igual y, en cualquier caso, no hay “reversión de la historia”. La violencia sigue galopante, la pobreza y la miseria mantienen toda su crueldad, muchos salvadorenios tienen que seguir emigrando, se mantiene intacta la dependencia del exterior, del Banco Mundial y del Fondo Monetario, de la globalización entendida desde (y para) una parte. Se mantiene y se acrecienta la inculturación a la inversa: cada vez somos menos salvadorefios, cantamos, vestimos, añoramos, vemos por televisión lo que otros han decidido por nosotros. Y lo malo de esto no es abrimos al exterior, por supuesto, sino la razón fundamental por la cual nos imponen estas cosas desde el exterior. el dinero. No sólo como individuos, sino como país somos considerados como "objeto consumidor".

Hay cambios, pues, pero poco hemos "revertido" la historia, y los poderosos no quieren ni ofr hablar de semejante posibilidad. $\mathrm{Y}$, sin embargo, sigue siendo necesaria. Hay cosas que no sólo hay que cambiar, sino revertir. Hay que revertir la devaluación de la palabra, que no se pueda decir todo impunemente: "vamos muy bien", dicen unos; "estamos muy mal", dicen las mayorías. Hay que revertir la parábola del rico Epulón y el pobre Lázaro, que es la expresión histórica, prolongada, antes, durante y después de la guerra, de nuestra situación.

La otra cosa tuya que quiero recordar, aunque sea brevemente, es sobre la Iglesia. Tu alegría con el Vaticano II, Medellín, Monseñor Romero, las 
comunidades de base era cosa clara. Eras, pues, eclesial. Pero dicho esto, exiglas cosas fuertes, criticabas cuando velas que la Iglesia no era la de Jesús o, peor aún, cuando era contraria a Jesús. Tú decías:

"La Iglesia deberia ponerse como misión universal histórica hacer volver a los hombres con ojos de misericordia a esa humanidad explotada y masacrada... Quizás salga asi una humanidad nueva y renazca así una Iglesia más resplandeciente, con menos manchas y arrugas, con mayor impetu profético, con mayor semejanza con Jesús muerto por nuestros pecados y matado por los ateos y asesinos de siempren.

Hay que revertir la tendencia pecaminosa de la Iglesia: su distanciamiento de los pobres, su cercanía a los poderosos, su discriminación intereclesial, el miedo que se introduce en ella para dialogar fraternalmente, para decir la verdad unos a otros.

También por lo que toca a la actuación eclesial nos recuerdan que las cosas han cambiado. No hay que ser anacrónicos, ni insensatos, ni masoquistas, nos dicen. Pero, respondemos, tampoco hay que engañar ni enganarse. No hay que mantener un cristianismo aguado que puede hablar por igual a victimas y a verdugos. No hay que hacer del cristianismo una gracia barata. Tal como estamos a altos niveles oficiales y curiales hay que revertir la tendencia a que la Iglesia no sea realmente salvadorefía, es decir, que no sufra con las angustias de los pobres y no goce con sus alegrías.

Cuando les recordamos a ustedes, Ellacu, recordarmos a una Iglesia que era - y debe ser- ante todo salvadoreña y real. Y recordamos también a una Iglesia santa, santificada por el trabajo y la entrega de cada día, y santificada con la sangre de amor.

Ellacu, termino con unas palabras que te escuché en un curso de eclesiología allá por el año 1980: "La última arma de la Iglesia de los pobres es la santidad". Yo creo que hay santidad entre nosotros, aunque quizás no sea como la pintan los libros espirituales. Creo que hay gente decidida, todavia hoy, a revertir la historia, aunque la mayoría de la gente sencilla lo haga con su diario vivir, sufrir y celebrar, y ni siquiera entienda la palabra. Creo que hay gente decidida a construir una Iglesia de los pobres, haciendo comunidad, formándose e instruyéndose, compartiendo y ejercitando la profecía. Creo que sigue habiendo santidad.

Lo que les pedimos a ustedes, sobre todo a los mártires salvadoreños, es que no nos dejen de la mano en estas dos tareas de revertir la historia y de construir una Iglesia de los pobres realmente salvadoreña. 